\title{
RESEÑA
}

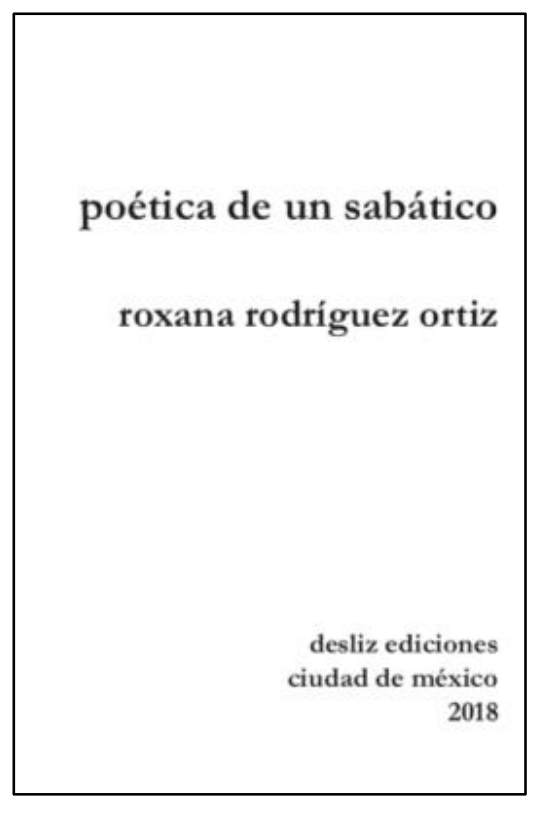

\section{PoÉTICA DE UN SABÁTICO}

Roxana Rodríguez Ortiz

Ciudad de México: Desliz ediciones, 2018

80 páginas

\section{Universidad AutónOMA DE LA CiUdAD DE MÉXico (México) exed.0460@gmail.com}

El ocio, según Aristóteles, es una especulación filosófica que permite la adquisición de la sabiduría. Se trata de vivir la experiencia y, a través de ella, adquirir conocimiento. Así, y por medio de su razón, el ser humano puede tener una mejor abstracción de su realidad. Al ser un ejercicio de reflexión, el ocio no se adquiere fácilmente y, para obtenerlo, es preciso acercarse a diversas áreas del conocimiento. Por ejemplo, a través de la historia se puede comprender cuál ha sido el proceso de la humanidad para alcanzar el prestigio que tiene en la actualidad. Asimismo, y entre tantas interrogaciones, la filosofía se pregunta por saber qué es el hombre, dejando como respuesta una herencia de tratados. Sin ser las únicas áreas de conocimiento, es preciso saber que a través de la poesía también es posible adquirir un momento de ocio. Se puede considerar a Poética de un sabático de Roxana Rodríguez como un homenaje al ocio, precisamente porque ofrece una pluralidad de temas que remiten a problemas contemporáneos en la ciudad de México y en otros lugares del mundo. De aquí se sigue que dicho libro no sólo permite disfrutar de la poesía, sino que, a su vez y sin tanta pretensión, exhorta a la reflexión.

En Poética de un sabático se presentan 51 poemas compuestos con inteligencia y que, en su conjunto, funcionan como piezas de un único 
rompecabezas interminable. 51 señales de locura. 51 dosis de realidad, dejando así un amplio repertorio de poemas para su lector. En este libro se reflejan las preocupaciones que le atañen a la autora, y que se vinculan con los acontecimientos diarios, de la rutina, del inconsciente, de lo social. Parece que este poemario es una declaración de amor y de odio. Lo cierto es que en la colección de poemas hay versos cortos, los cuales pueden significar mucho, o incluso no decir nada. Deducirlo es relativo, dado que depende de la interpretación que cada lector pueda dar. En este mismo sentido, se puede decir que, así como hay una diversidad de versos, hay una variedad de vivencias que el mismo lector puede conectar con el texto. Considero que su índice es idóneo para leerlo sin seguir una secuencia, lo que facilita la preferencia por algún poema.

Siguiendo esta línea, el lenguaje que ofrece la autora es sencillo y peculiar, lo cual le permite a su lector tener un rato ameno y acercarse a los conceptos utilizados. Por todo lo anterior, resulta conveniente señalar que la obra contiene una reflexión que abarca lo complejo del ser humano y lo problemático que es su absurdo ego. Se trata, además, del primer libro de poesía escrito en un año sabático — de ahí el origen del título—, con una colección de poemas que permite leer a la autora en otro formato y en la que, a su vez, se manifiestan sus inquietudes filosóficas, logrando así un vínculo entre poesía y filosofía.

Lo que se lee en este libro no es sólo una lista de versos, sino una manifestación de su persona, un vuelo de sí y para los demás. Se destaca también el trabajo de Roxana Rodríguez al recuperar conceptos de sus obras anteriores; entre éstas, por ejemplo, Cartografía de las fronteras. Diario de un campo (2016), que sigue una investigación sobre la frontera de México-Estados Unidos. De esta manera, el trabajo que concierne a la autora es sobre una filosofía de las fronteras, y algunos de los conceptos presentes en dicha investigación son importantes para presentar un texto novedoso como Poética de un sabático, donde se encuentran versos que denotan problemas de la frontera y la migración. Lo anterior se refleja principalmente en los siguientes fragmentos: "Aún así, migrar siempre cala. La nostalgia de saberte lejos hasta que adoptas otro saber-estar" (27). Algunos de los versos que corresponden a este primer poema son oscuros al pintar la realidad de los migrantes. Pareciera entonces que éstos no se encuentran a sí mismos, precisamente porque no se sienten parte de ningún lugar. En el segundo poema se deja ver que hay una manifestación de lo que ocurre en la actualidad y de los daños causados en las personas que tratan de cruzar la frontera, anhelando un sentimiento de calma. " $12 \mathrm{~km}$ de frontera. Una división artificial. Una ida sin vuelta. Un deseo censurado” (58).

El presente libro también ofrece palabras que versan sobre temas escabrosos. Algunos de éstos reflejan una problemática presente tanto en la Ciudad de México como en el resto del mundo. Por ejemplo, en el poema que lleva por nombre: "Mientras matan mujeres"(74). Los versos que lo componen dejan ver claramente una verdad incómoda, dado que no todos los casos de feminicidio son resueltos. Estos acontecimientos hacen notar que en la Ciudad de México se refleja un dominio político hetero-patriarcal sostenido por ideas 
retrógradas y que, a su vez, sustentan un orden capitalista. Este modelo político es justamente lo que impide mirar a otros horizontes y ver que ser mujer, homosexual, lesbiana, transexual, pobre o indígena no son más que conceptos ontológicos para señalar al "otro", a aquél que no tiene cabida en un mundo donde el poder masculino predomina. Tras esto, la autora, quien conoce del tema, ha decidido anunciar su pensar; transmitir y denunciar, a través de la poesía, el acto macabro de los feminicidios, clamando así consciencia y justicia para las mujeres asesinadas por defender sus derechos. En la obra se halla también una referencia al asesinato de los periodistas, justo en el poema 41. Del mismo modo, Roxana Rodríguez hace referencia al tema de los desaparecidos, en particular de los 43 normalistas de Ayotzinapa: "\#AyotzinapaSomosTodos" (69).

Otros textos remiten a cuestiones filosóficas. Por ejemplo, "Escribo con retraso y retardo", "El reloj no se detiene" y "Año bisiesto". Los tres poemas se relacionan entre sí, precisamente porque hacen referencia a un concepto que puede agobiar. Y es que hablar del tiempo es algo complejo. Entre tantas teorías, existe la de Immanuel Kant, quien dijo que el tiempo es una condición de la intuición, lo cual le permite al ser humano adquirir experiencia y conocimiento; en otras palabras, es algo intuitivo y subjetivo. Albert Einstein, por su parte, afirma que es relativo. Sin embargo, el tiempo también se ha usado como metáfora en la poesía, justo como lo hizo Borges al decir que este concepto es angustia. La excepción no se hace en la poesía de Rodríguez, al decir justamente lo siguiente: "La ciudad me come, el tiempo me paraliza" (30) o "que el tiempo no se detiene, si nos acercáramos a la velocidad de la luz, quizá seriamos infinitos" (27). Asimismo, hace referencia al tiempo de la siguiente manera: "el tiempo es tan relativo como el año bisiesto" (79). De modo que los tres poemas permiten una reflexión en relación con el tiempo y, quizá, con la finitud del ser humano. Posiblemente y después de leer estos versos surjan interrogantes por parte del lector, tales como: ¿El objeto al que llamamos reloj, contiene el tiempo? ¿Puedo obtener un trozo de tiempo? ¿Qué es el tiempo? O muy posiblemente se pregunte si de aquel verso puede extraerse alguna interpretación.

A diferencia de los otros poemas, Poética de un sabático también expresa versos que remiten al amor. De esto último se puede deducir que los poemas son dedicados a alguien en particular. Sin embargo, pensar esto puede ser un error, pues muy pocas veces se sabe cuál es la intención del autor. Pretender universalizar el sentido de un poema también es un error, dado que muchas veces su autor no sabe en manos de quién ha caído el poema que a nadie dedicó; sino que es el amor al arte el primer motor, el cual hace genuino el momento de la escritura. De aquí se sigue que la interpretación de algún poema será innumerable, $y$, por tanto, no se puede pretender universalizar un mismo sentido. No obstante, las expresiones de amor no dejan de manifestarse en el poemario que presenta Rodríguez. Por una parte, se encuentra el poema: "Disfruto el coqueteo" (28), quizá sea la composición de sus versos que aluden a la pasión, al encuentro misterioso entre dos personas que sólo quieren disfrutar de un momento de seducción. Otro poema que abarca el sentimiento del amor 
es el que se denomina "Sobre los amantes" (50). Éste contiene versos que se refieren a todos aquellos que se aman de una manera incondicionada, en donde expresan sus genuinos sentimientos. No obstante, hay un poema que deja ver la faceta más romántica de la autora y dice lo siguiente: “¿Me amas? pregunta en vela quien ha forjado la pasión sobre la devoción" (54). Sin la etiqueta de una dedicatoria, los versos que forman el poema son una señal del gusto que siente la autora por escribir poesía.

Resumiendo, Poética de un sabático deja en claro que en momentos de ocio (reflexión) se puede escapar un rato de la realidad a través de la poesía; un escape que, paradójicamente, puede llevar a todo lector de la poesía a la realidad, y esta vez con un criterio más amplio. La poesía no es fantasía, ni tampoco son los delirios de un loco con razón. Es, en cambio, un encuentro con la realidad y su máxima expresión ontológica, aquel estudio del ser en tanto que ser, preocupación de una ontología pura. Como la de Heidegger, quien habló del Dasein como un ser arrojado en el mundo, el cual se busca a sí mismo después de formularse la pregunta que interroga por el ser. La poesía cruza la frontera entre lo real y lo imaginario. En la poesía se discute con los sucesos que se viven día a día, y de igual manera se encuentra el vínculo con la filosofía. En este poemario se hallan problemas que aún pueden ser tratados, desde lo social hasta lo sentimental. Esto último no le es ajeno a la responsable del libro, pues en él ha plasmado más de una vez que el amor no sólo es un misterio, sino algo que se vive, que se experimenta. Rodríguez nos expresa el misterio del amor, dejando en claro que puede existir más de una forma de amar; entre tanto, amor por los libros, amor por el arte. Y lo mas preciado de todo, es que lo escrito, además de abordar problemas contemporáneos, se ha plasmado con la intención de no ser borrado, mucho menos olvidado. Derrida ha acertado al decir que un poema nunca muere, pues mientras se siga leyendo, mientras se siga interpretando, seguirá vivo. La poesía no ha muerto ni muere con su autor.

Así, el poemario que se ha comentado expresa una exhortación a la reflexión; no porque el contenido sea técnico y abrumador, sino porque al no exigir un orden se puede leer, incluso, de final a principio. De cualquier forma, el lector puede encontrar un concepto o una palabra clave que le hará pensar en una posible interpretación y ajustar, quizá, el contenido a su propia realidad. Un libro que fue escrito en un rato de ocio, y que ahora puede significar mucho o poco. Realmente, esta colección de poemas no exige demasiado al lector, salvo que tome el vuelo de la poesía y se permita un momento de reflexión; cuente 43 segundos para decidir si quiere ser políglota o pensar en el año bisiesto. 